\title{
Feeding by Chaetognatha: The Relation of Prey Size to Predator Size in Several Species
}

\author{
S. Pearre, Jr. \\ Department of Oceanography, Dalhousie University, Halifax, N.S. B3H 4J1, Canada
}

\begin{abstract}
The mean size of prey items, measured as body width $(H)$, is related to chaetognath predator head width ( $P$ ) of several chaetognath species as a power curve: $H=a P^{b}$ with ' $a$ ' varying between 0.33 and 0.86 and ' $b$ ' between 0.27 and 0.82 . This is the expected general form of the relationship when predators and prey have different allometric exponents. There are a number of artefacts of laboratory and statistical analyses which can affect the magnitudes of these coefficients. In general, however, real differences in the prey/predator size relationship seem to exist between species, and within species in different areas. Because chaetognaths are probably one of the main sources of predation pressure on the copepod community, both the general form of their prey-size selection and differences in this function between species should have considerable influence on the size structures of lower trophic levels.
\end{abstract}

\section{INTRODUCTION}

The phylum Chaetognatha, despite being morphologically undiverse, has come to be recognized as one of the most important groups of pelagic predators in the world ocean (Reeve, 1970). Because of their ubiquity and principle predation on copepods, chaetognaths are probably major factors in the structuring of most marine ecosystems (Steele and Frost, 1977).

The only experimental study of prey-size selection in a chaetognath so far was that of Reeve and Walter (1972). However, like most fish and the majority of other pelagic carnivores, chaetognaths swallow their prey whole. This feature, combined with their natural transparency, makes examination of their gut contents relatively simple, and has led to a number of field studies of their predation.

In this paper I will attempt to bring together and compare all of the available data and determine the form of the relationship of prey size to chaetognath size in terms of their relevant controlling linear dimensions.

Among predators which swallow prey whole, mean prey size should bear some simple relation to predator size (Kerr, 1974). Studies on prey selection in fish suggest that mean prey weight declines relative to predator weight, and the best representation for most is a power curve

$$
W_{H}=\alpha W_{p}^{\beta}
$$

where $W_{H}=$ mean weight of prey individual; $W_{p}=$ mean weight of predator individual; $\alpha, \beta=$ fitted constants; $\beta<1$.

Suppose that prey weight is related to a linear parameter such as body width (B) by another power function, the usual allometric relation

$$
W_{H}=a_{H} B^{b_{H}}
$$

and the predator weight is a similar function of some linear dimension, in this case mouth width:

$$
W_{p}=a_{p} M^{p_{p}}
$$

Substituting these relationships in (1) and rearranging, we obtain another power curve:

with

$$
\begin{gathered}
B=a M^{b} \\
a=\left[\frac{\alpha \cdot a_{p}{ }^{\beta}}{a_{H}}\right]^{\frac{1}{b_{H}}} \\
b=\frac{b_{p} \cdot \beta}{b_{H}}
\end{gathered}
$$

Kerr (1974) and Sheldon et al. (1977) suggested that prey weight should be a constant fraction of predator weight, i.e. $\beta$ (above) $=1$. Two sets of data are available for evaluating $\beta$ in chaetognaths. Data of Mironov (1960) on food of 'Sagittae' (mainly S. setosa Müller) in the Black Sea give a best fit, of four tested regression models, to the power curve with $\beta=0.30$ (as mg wet weight). Data from Feigenbaum (pers. comm.) on $S$. elegans Verrill off Woods Hole, USA also best fit this model with $\beta=0.23$ (as $\mathrm{mg}$ dry weight). 
Kerr (1974) further proposed that mean prey and predator linear dimensions would also be in constant proportions. Even if $\beta=1$, this latter result would only be true if $b_{H}=b_{p}$ (Kerr assumed isometry for each, i.e. $b_{H}=b_{p}=3$ ).

Werner (1974) did find that optimal body depth of fish prey was a constant fraction of fish predator mouth size, but noted that mouth size itself decreased relative to fish length, i.e. optimal prey width in fact decreased relative to predator length. Reeve and Walter (1972) found that, although in the chaetognath Sagitta hispida Conant mouth width remains relatively constant with respect to body size, mean prey size decreases relative to mouth size, effecting the same result.

Pearre (1980) showed that wet weight of a large number of copepod species could be predicted as a single power function of body width. Thus, since copepods are numerically the dominant prey item of chaetognaths, we can as a first approximation consider $a_{H}$ and $b_{H}$ as constants. If we assume that $\beta$ is also constant within and between chaetognath species, $b$ should differ between chaetognath species in proportion to their own allometric exponents $\left(b_{p}\right)$. In practice, however, $\beta$ may vary due to prey distribution and densities, as will be discussed below. If non-copepod prey are significant, $b_{H}$ may vary as well.

\section{MATERIAL AND METHODS}

Zooplankton was collected in Bedford Basin, Halifax (Canada) at seven depths over different times of day through two 24-h periods (July 17-18 and Dec. 12-13, 1967) at a deep station (Pearre, 1973). Collection was done with a $12.7 \mathrm{~cm}$ Clarke-Bumpus closing net fitted with $0.239 \mathrm{~mm}$ mesh nets. In each tow the nets were open for $4 \mathrm{~min}$ and filtered $1.5-2 \mathrm{~m}^{3}$ of water. Immediately after retrieval, samples were preserved with buffered formalin

Due to high plankton density, only $1 / 8$ of each July sample was sorted for Sagitta (Folsom plankton splitter). All chaetognaths which had opaque regions in the gut indicating possible food remains were removed, measured, and examined microscopically for prey in Hoyer's (water-miscible) mounting medium. In larger specimens with rather opaque body walls, this was done by dissection; smaller ones were occasionally whole-mounted.

Prey were identified to species, sex, and stage where possible. Due to lateral compaction of well-digested copepod remains it was generally not possible to measure prey width directly, but lengths of all hard-bodied prey were determined (generally prosome lengths in copepods). Most hard-bodied prey were copepods; the major hard-bodied prey remains in the smallest chaetognaths were the loricae of tintinnids, which were not identified to species but were measured in both dimensions.

Approximate body widths were calculated for each prey item which had been identified in sufficient detail. Lengths and widths of all stages $\left(\mathrm{N}_{1}-\mathrm{C}_{6}\right)$ of common copepod species in Bedford Basin at the appropriate times of year were determined (a) by direct measurement on some stages and species from the Clarke-Bumpus hauls, (b) from measurements on Pseudocalanus sp. from the same samples (Lock, 1968), (c) from seasonal length measurements of various species compiled by Poulet and Conover (unpublished), and (d) from general literature sources on relative sizes of small copepodite and naupliar stages of these species.

Rakusa-Suszczewski (1969) examined the diets of Sagitta elegans and $S$. setosa from the seas around Great Britain. These samples were collected with a vertically towed 'standard Hensen net'; mesh was unspecified but if truly standard would have been about $0.33 \mathrm{~mm}$ (Sverdrup et al., 1942). Copepod prey abundances and lengths were reported in graphical form. I scaled these off to produce an approximate table of chaetognath size classes and prey widths lobtained from prey length data by the same process as for the Bedford Basin data: the two study areas in fact contained mostly the same species).

Sizes of prey Sagitta setosa from the Black Sea were obtained by reconstruction of diet and/or prey-size selection data given by Mironov (1960) and information on the sizes of the various prey species in this area (Petipa, 1957; Studenikina and Cherepakhina, 1969).

Prey ingested by Mediterranean species (Sagitta enflata Grassi, S. friderici Ritter-Zahony', and $S$. minima Grassi) were obtained from two sample sets each at four depths from stations in the West-Mediterranean near Barcelona. Series 'A' (Pearre, 1974) was a 24-h study and Series 'B' (Pearre, 1976) was a monthly, year-long study. Prey copepods were measured where possible; other width values were obtained from the literature.

Reeve and Walter's (1972) experimental feeding results were reconstructed from their Figures 1 and 2. It was assumed that the prey size data are already in

\footnotetext{
- This species was originally reported by me (Pearre, 1974) as Sagitta bipunctata Quoy and Gaimard. Subsequently, A. Alvarino re-identified them for me as $S$. friderici and I made this change for a second manuscript (Pearre, 1976). Dallot (1978) has stated that they probably were in fact $S$. setosa Mueller, and Andréu (1979) does not list S. friderici as occurring in the region. For simplicity I retain the name 'S. friderici' here, but note that with the appropriate head width conversion (0.76, from Table 1) these data fit plausibly with those for S. setosa (Figs 4 and 6)
} 
terms of widths, as the size classes of offered prey were determined by sieving.

Estimates of chaetognath head widths were obtained from length data (front of head to end of body not including tail fin) by application of a ratio obtained by direct measurements and from literature sources. All measurements were taken with the chaetae in the closed position, which somewhat underestimates the functional mouth size, as the head width increases when the chaetae (grasping spines) are extended to catch prey. Kotori's (1976) drawings indicate negligible change in the head width/body length ratio over the life-time of f e e d ing stages in Sagitta elegans, and Reeve and Walter's (1972) data show no significant changes in the ratio for $S$. hispida Conant. The ratios used are given in Table 1; a list of the literature sources can be supplied by the author.

Table 1 . Head width/body length ratios $(\mathrm{h} / \mathrm{b})$ estimated for various Sagitta species

\begin{tabular}{|lccc|}
\hline \multicolumn{1}{|c}{ Species } & $\mathrm{h} / \mathrm{b}$ & $\begin{array}{c}\text { Number of } \\
\text { estimates }\end{array}$ & $\begin{array}{c}\text { Number of } \\
\text { references }\end{array}$ \\
\hline S. elegans Verrill & .0517 & 22 & 11 \\
S. enflata Grassi & .0758 & 24 & 13 \\
S. friderici & & & \\
$\quad$ Ritter-Zahony & .0710 & 6 & 6 \\
S. hispida Conant & .0782 & 16 & 9 \\
S. minima Grassi & .0460 & 10 & 8 \\
S. setosa Mueller & .0540 & 13. & 7 \\
\hline
\end{tabular}

For comparability, all data sets were analysed by a Model I regression for grouped data (Sokal and Rohlf, 1969; Box 14.4). The regression models tested were linear $(H=a+b P)$, exponential $\left(H=a e^{b P}\right)$, logarithmic $(H=a+b \ln P)$ and double-logarithmic or power curve' $\left(H=a P^{b}\right)$. Data from the literature were always grouped into predator size classes containing variable numbers of observations. For these, data points were weighted by the number of observations in each class (Mather, 1943).

Significance of the regression was calculated as a 'Student's-t'test, using the square root of the ratio of the mean square for regression to that for deviations from regression after removal of the term for within-group variance (Sokal and Rohlf, 1969). In all cases this test was more conservative than pooling within-group variance in the error term. Differences between regression coefficients were tested by analysis of covariance (Sokal and Rohlf, 1969; Box 14.8). Differences between positions of regression lines (expressed as differences between a values) were tested by comparisons of the means (Mather, 1943).

Significances are expressed as probabilities of the null hypothesis and denoted by the convention (Sokal and Rohlf, 1969): ${ }^{*}=0.05>\mathrm{p}>0.01 \mathrm{i}^{\cdots}=0.01>\mathrm{p}>$ $0.001 ; \cdots=\mathrm{p}<0.001$.

\section{Notes on Calculations of Regressions}

The regressions tested were of ordinary (Model I; Sokal and Rohlf, 1969) form. In theory, a Model II regression should have been more appropriate because both variables were subject to error, but in practice these seem to improve the accuracy very little while possibly (depending on the method) greatly increasing the difficulty of calculation, or discarding considerable information (Sokal and Rohlf, 1969). An alternative to Model II regressions, the so called 'geometric mean' (G.M.) regression has been recommended by Ricker (1975). Geometric mean regressions were unsuitable for these data for several reasons, of which the most forceful stem from the fact that a chaetognath of any given size could have eaten prey of a wide range of sizes. Thus for any $X$, the variance in $Y$ was considerable, and due to different causes than that of the variance in $X$ (c. f. Ricker, 1975).

The effects of this can best be illustrated as follows: for any predator size class, there exists a mean prey size, and the true representation of the mean prey/ predator size relation will be a line joining these means of each predator size class. This is equivalent to saying that the single regression line best describing this relation is in fact that minimizing the sums of squares in prey sizes $(Y)$ at any predator size $(X)$. This is the rationale of the ordinary ( $Y$ on $X$ ) regression, while the G. $M$. regression essentially combines this with an $X$ on $Y$ regression, i.e. treats each $X, Y$ pair as independent. In practice, mean prey size was invariably a larger fraction of predator size in small than in large predator size classes yet G.M. regressions often yielded slopes greater than unity.

\section{RESULTS}

Of the four tested regression models, the 'power curve' $\left(H=a P^{b}\right)$ was the best fit in the largest number of cases (Table 2); with $H=$ prey body width; $P=$ chaetognath head width. It was adopted as representing the predictive relationship between linear dimensions of predator chaetognaths and their prey.

The July and December data from Bedford Basin were found to differ neither in slope nor position (Table 3), indicating that Sagitta elegans selected prey similarly in summer and winter. The two sets were thus combined to form a 'Bedford Basin' curve (Table 3, Fig. 1) Rakusa-Suszczewski's (1969) data on $S$. elegans from British seas, however, yields a considerably 
Table 2. Rankings of the four tested regression models in terms of $r^{2}=$ proportion of variance explained by regression

\begin{tabular}{|c|c|c|c|c|c|}
\hline $\begin{array}{l}\text { Sagitta } \\
\text { species }\end{array}$ & $\begin{array}{c}\text { Linear } \\
H=a+b P\end{array}$ & $\begin{array}{l}\text { Exponential } \\
\qquad H=a e^{b P}\end{array}$ & $\begin{array}{l}\text { Power } \\
H=a P^{b}\end{array}$ & $\begin{array}{c}\text { Logarithmic } \\
H=a+b 1 n P\end{array}$ & Source \\
\hline S. elegans & 3 & 4 & 1 & 2 & This study \\
\hline S. elegans & 3 & 1 & 2 & 4 & Rakusa-Suszczewski (1969) \\
\hline S. enflata & 3 & 4 & 2 & 1 & This study \\
\hline S. friderici & 4 & 3 & 1 & 2 & This study \\
\hline S. hispida & 3 & 2 & 1 & 4 & Reeve and Walter (1972) \\
\hline S. minima & 4 & 3 & 1 & 2 & This study \\
\hline S. setosa & 3 & 1 & 2 & 4 & Rakusa-Suszczewski (1969) \\
\hline S. setosa & 4 & 2 & 1 & 3 & Mironov (1960) \\
\hline Mean rank & 3.4 & 2.5 & 1.4 & 2.8 & \\
\hline
\end{tabular}

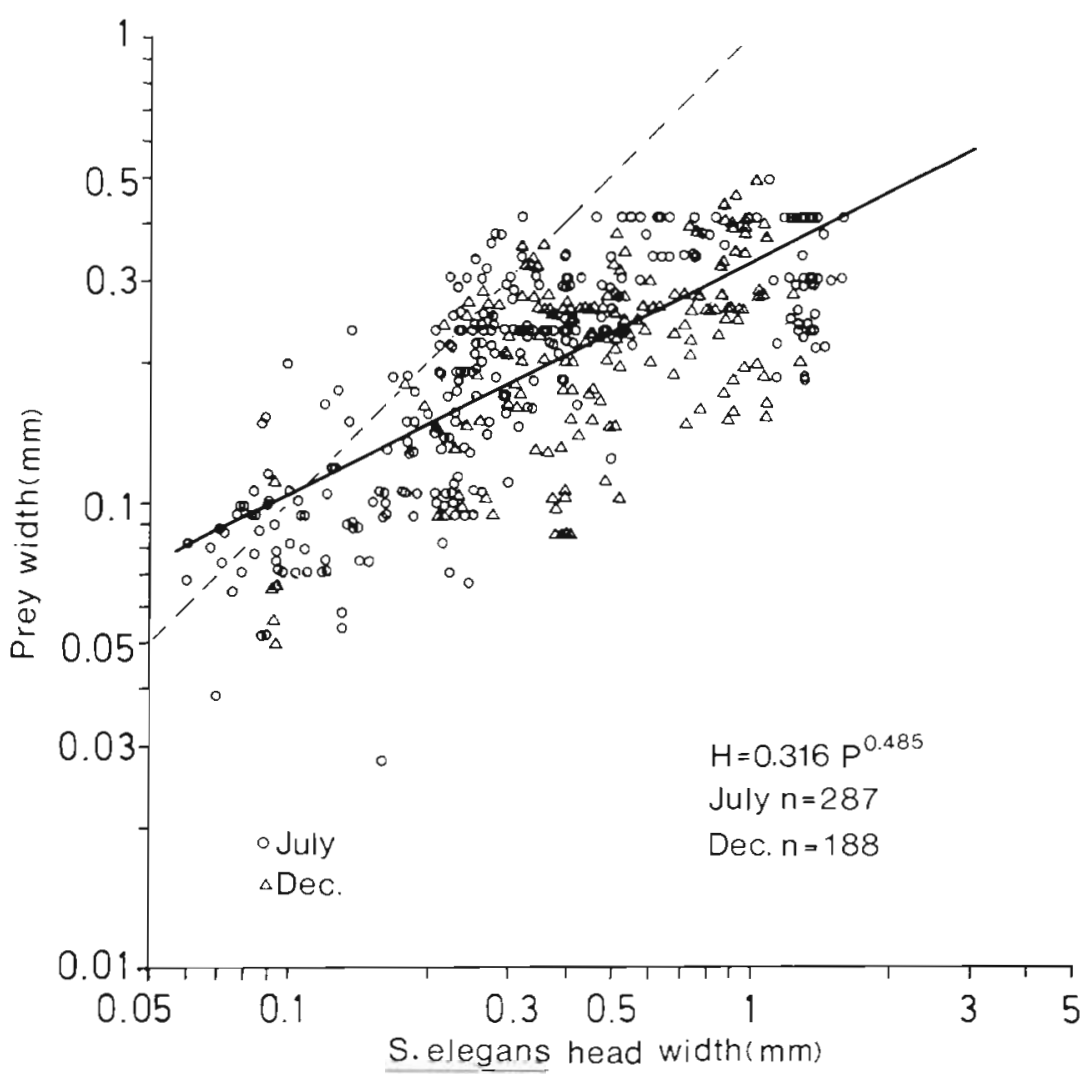

Fig. 1. Prey width vs predator head width for Sagitta elegans; Bedford Basin, N.S. (Canada). July 17-18,1967; December 12-13, 1967. Broken line shows 1:1 ratio

Table 3. Mean prey size vs chaetognath (Sagitta elegans) size in Bedford Basin, N.S. (Canada), as $H=a P^{b} ; H=$ maximum width of prey $(\mathrm{mm}) ; P=$ head width of chaetognath $(\mathrm{mm}) ; a, b=$ fitted constants

\begin{tabular}{|c|c|c|c|c|c|c|}
\hline Date & No. prey & No. groups & a & $b$ & $r^{2}$ & $t_{(g)}$ \\
\hline July $17-19,1967$ & 289 & 156 & 0.3326 & 0.5067 & 0.616 & $19.363 \cdots$ \\
\hline \multirow[t]{2}{*}{ Dec. $12-13,1967$} & 188 & 114 & 0.2957 & 0.4516 & 0.331 & $9.437 \cdots$ \\
\hline & $\begin{array}{l}\text { Test for differ } \\
\text { Test for differ }\end{array}$ & $\begin{array}{l}\text { ween ' } a \text { ' valu } \\
\text { ween ' } b \text { ' valu }\end{array}$ & & & & $\begin{array}{l}0.16 \\
1.03\end{array}$ \\
\hline Combined sets & 477 & 260 & 0.3161 & 0.4851 & 0.535 & $21.725^{\cdots}$ \\
\hline
\end{tabular}


Table 4. Mean prey size vs Sagitta elegans size., as $\mathrm{H}=a P^{b} ; H=\max$. width of prey (mm); $P=$ head width of $S$. elegans (mm); $a, b=$ fitted constants

\begin{tabular}{|c|c|c|c|c|c|c|}
\hline Data set & No. prey & No. groups & $a$ & $b$ & $r^{2}$ & $t_{(g)}$ \\
\hline $\begin{array}{l}\text { Rakusa-Suszczewski (1969); } \\
\text { seas around Britain }\end{array}$ & 1276 & 20 & 0.6221 & 0.7665 & 0.358 & $11.352 \cdots$ \\
\hline $\begin{array}{l}\text { Combined Bedford Basin } \\
\text { (July }+ \text { December, 1967) } \\
\text { Truncated at } P \leq 0.4\end{array}$ & 258 & 137 & 0.4928 & 0.7559 & 0.500 & $14.89^{\cdots} \cdot$ \\
\hline
\end{tabular}

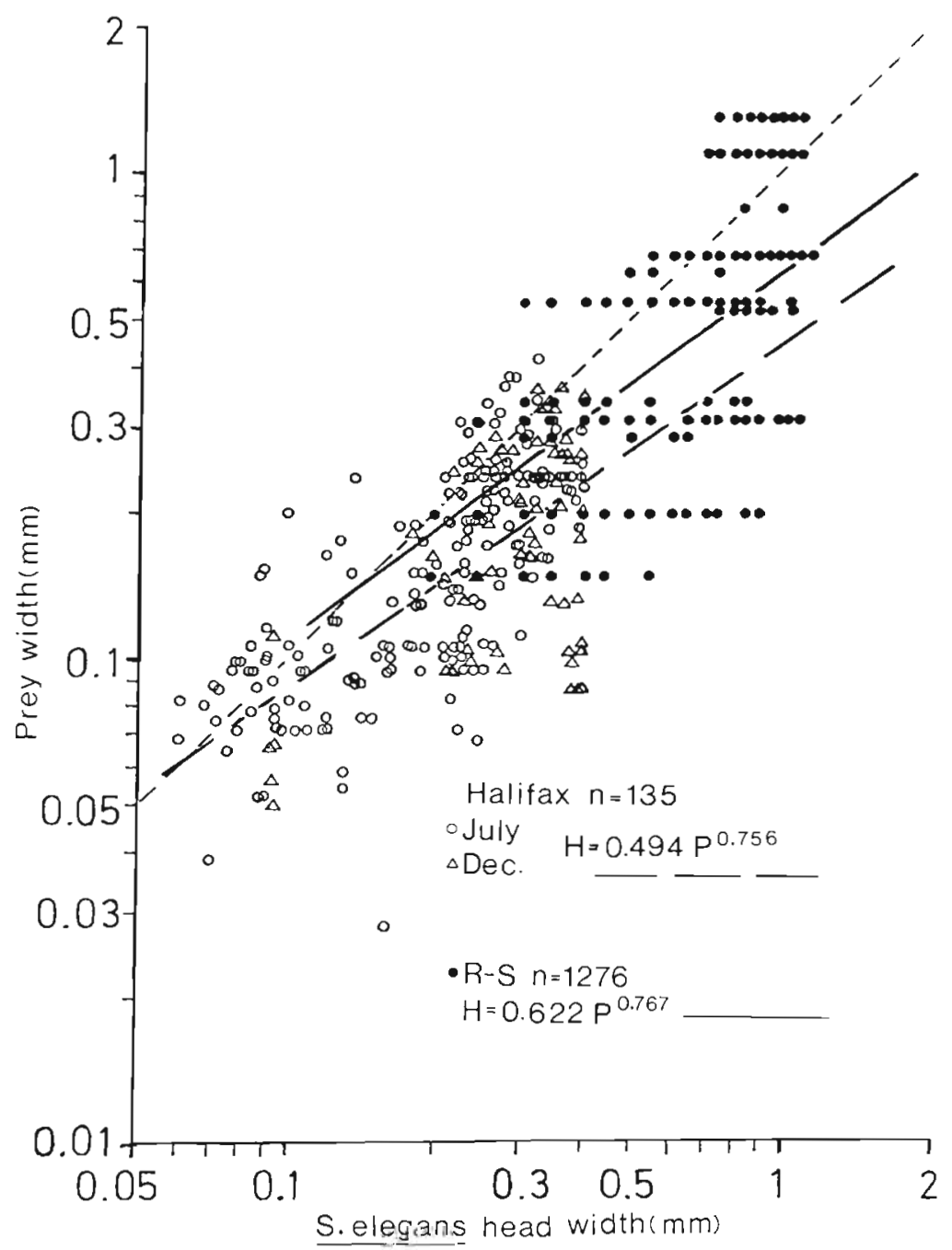

Fig. 2. Prey width vs predator head width for Sagitta elegans. - R-S: data reconstructed from Rakusa-Suszczewski (1969), with each point weighted for the number of observations in that size class. $O$ and $\Delta$ : data from Bedford Basin (Halifax) as in Figure 1 , but truncated at chaetognath head width $\leq 0.4 \mathrm{~mm}$

steeper curve (Table 4, Fig. 2). A priori, it seemed most reasonable that a given species should select prey in the same manner in different locations, especially in view of the demonstration that size-selection was seasonally constant in one location. Examination of the Bedford Basin data (Fig. 1) appeared to show a 'shoul- der' in the distribution at a chaetognath head width somewhere between 0.3 and $0.4 \mathrm{~mm}$. Above this, maximum prey sizes appeared to level off rather abruptly at about $0.4 \mathrm{~mm}$ width, while no such change occurred in the Rakusa-Suszczewski data. In the latter study, prey above this size were strongly dominated by 
copepodids and adults of Calanus finmarchicus, an uncommon species in Bedford Basin, which was not found in either the water column or chaetognath gut contents in either sample set. On the assumption that this 'shoulder' in the data was caused not by feeding preference but by prey availability, regressions were calculated on the Bedford Basin data truncated at head width values of 0.3 and $0.4 \mathrm{~mm}$. Both regressions have slopes very similar to, and bracketing that of the Rakusa-Suszczewski data (Table 4); thus the steeper slope appears to represent 'free choice' prey selection. The regression truncated at $0.4 \mathrm{~mm}$ (as the more conservative) is plotted with the Rakusa-Suszczewski data in Figure 2.

While the truncation of the Halifax data raises the position of the line (as represented by the a value, Table 4), there remains a difference between the mean prey size relative to the chaetognath size in the two data sets. This difference may result from failure of Rakusa-Suszczewski to record predation on small copepods, especially Oithona similis (= helgolandica), which were eaten selectively by most sizes of Sagitta in Bedford Basin (Pearre, 1973). Oithona is rapidly digested, and generally was found only as mandible cutting edges in Sagitta guts, but they were common in the zooplankton and their effect on mean prey size has probably been underestimated even in the Bedford Basin data. Sullivan (1980) has reported that Oithona

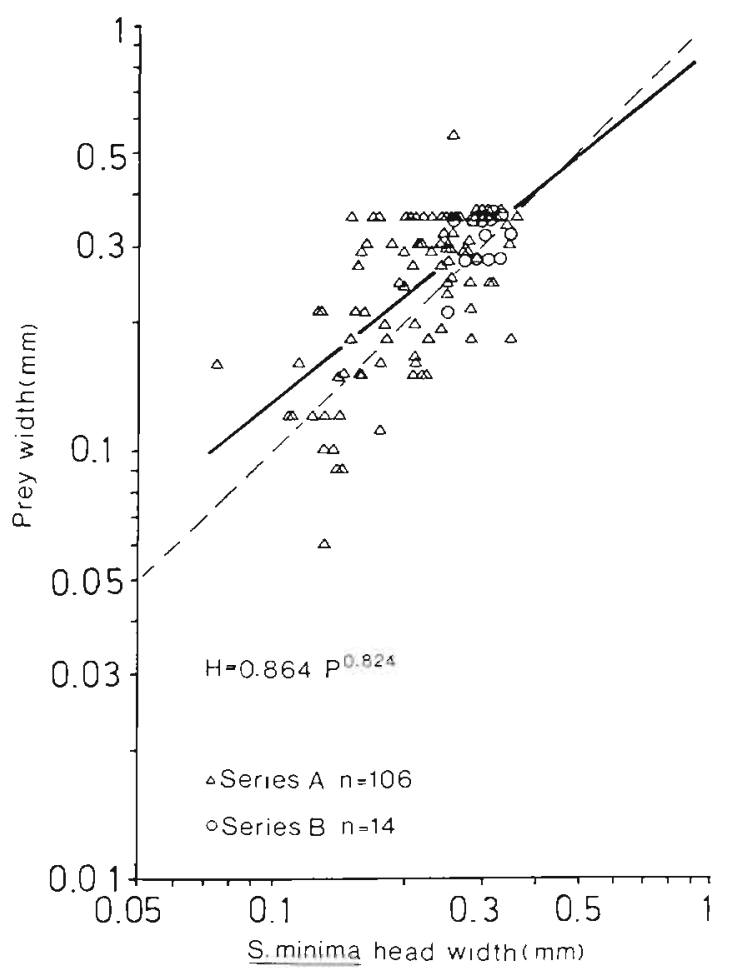

Fig. 3. Prey/predator size relation for Sagitta minima. Data from Pearre $(1974,1976)$ similis is numerically by far the most common prey of $S$. elegans in the North Pacific. Oithona spp. were also very common in the area examined by Rakusa-Suszczewski, yet were reported only 35 times out of some 3900 prey items identified in two studies. Thus the true a for the regression of prey width to predator head size for Sagitta elegans is probably closer to that for Bedford Basin, or perhaps even somewhat lower.

There were no statistically significant differences between the Series 'A': (24-h) and Series 'B' (all year) prey-size/predator-size regressions for the three westMediterranean species, so these were combined to give single regressions for each species (Table 5 and Figs 3, 4, and 5).

Rakusa-Suszczewski's (1969) data for Sagitta setosa from seas around Britain are plotted in Figure 6 with

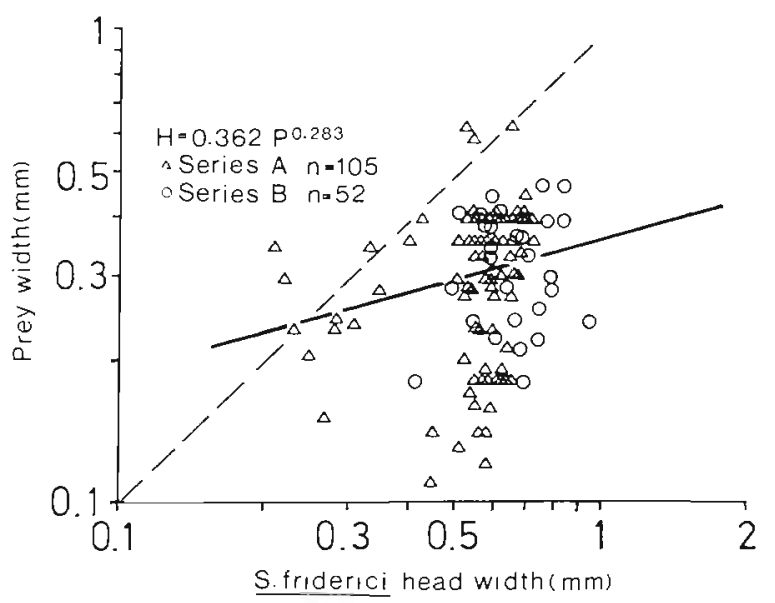

Fig. 4. Prey/predator size relation for Sagitta friderici. Data from Pearre $(1974,1976)$

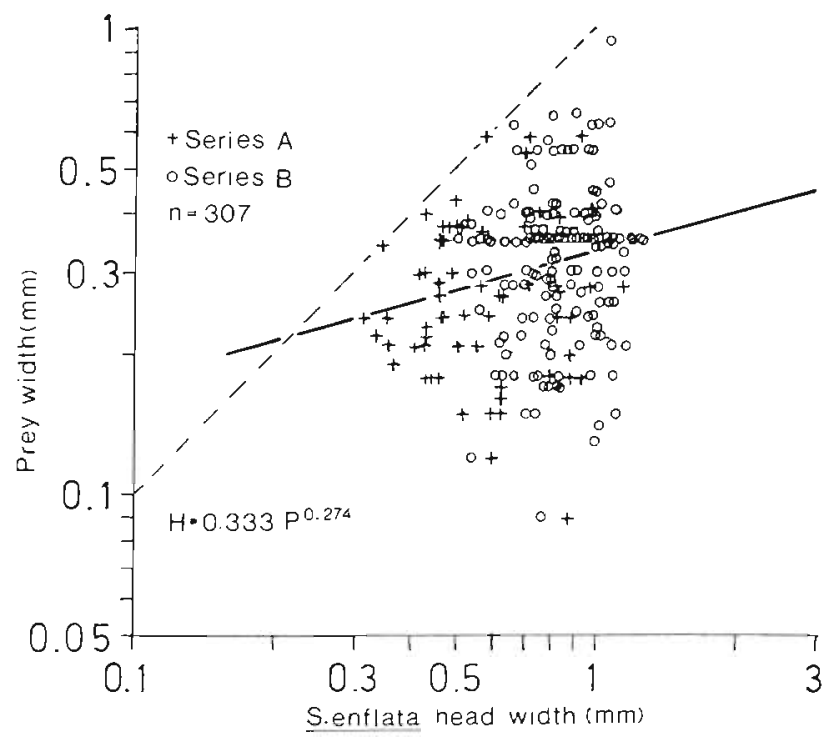

Fig. 5. Prey/predator size relation for Sagitta enflata. Data from Pearre $(1974,1976)$ 
Table 5. Western Mediterranean chaetognath (Sagitta) studies: regression of prey width (H) vs chaetognath head width $(P)$ as $H=a P^{b}$; Series A: May 30-31, 1966; Series B: May 1967-April 1968

\begin{tabular}{|c|c|c|c|c|c|c|c|}
\hline Species & Series & No. prey & No. groups & $a$ & $b$ & $r^{2}$ & $t$ \\
\hline \multirow[t]{3}{*}{ S. minima } & A & 106 & 49 & 0.947 & 0.877 & 0.401 & $7.255 \cdots$ \\
\hline & $B$ & 14 & 13 & 0.281 & -0.050 & 0.0005 & 0.072 \\
\hline & combined & 120 & 52 & 0.864 & 0.824 & 0.388 & $7.248^{\cdots}$ \\
\hline \multirow[t]{3}{*}{ S. friderici } & A & 105 & 42 & 0.360 & 0.300 & 0.051 & $2.173^{\circ}$ \\
\hline & $\mathrm{B}$ & 52 & 30 & 0.320 & -0.061 & 0.001 & 0.241 \\
\hline & combined & 157 & 53 & 0.362 & 0.283 & 0.044 & $2.565^{\circ}$ \\
\hline \multirow[t]{3}{*}{ S. enflata } & A & 89 & 49 & 0.286 & 0.114 & 0.010 & 0.874 \\
\hline & $\mathrm{B}$ & 218 & 73 & 0.340 & 0.198 & 0.013 & 1.733 \\
\hline & combined & 307 & 94 & 0.333 & 0.274 & 0.043 & $3.690 \cdots$ \\
\hline
\end{tabular}

Mironov's (1960) data on the same species from the Black Sea. Although the Black Sea specimens are smaller, the regressions are very similar and do not differ in slope $(t=0.084)$.

The reconstruction of Reeve and Walter's (1972) data for experimental feeding of Sagitta hispida appears in Figure 7.

In many cases (Figs $1-7$ ) prey widths exceed calculated chaetognath head widths. This is not unreasonable because, as discussed above, the head expands considerably when capturing prey (Sullivan, 1980) and copepods are also somewhat compressible in width.

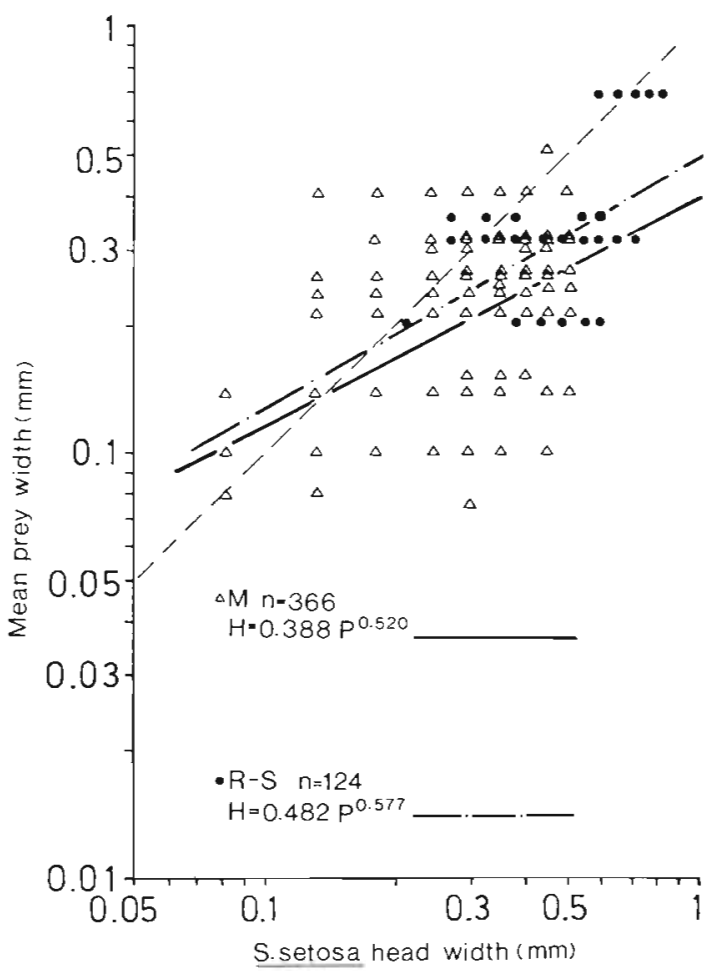

Fig. 6. Prey/predator size relations for Sagitta setosa. $\triangle$ M: e.c. weighted data from Mironov (1960); • R-S: ditto from RakusaSuszczewski (1969)

\section{DISCUSSION}

It is gratifying that the best-fit regression model, chosen solely on the basis of $r^{2}$, is of the same form as that expected on the basis of allometry. However, many factors contribute to uncertainty in determination and meaning of specific prey/predator size regressions. Pearre $(1974,1979)$ and others have discussed problems related to determination of the items ingested, as opposed to the remains found. Unless such errors are systematic, however, they may not greatly affect the regression line.

One source of systematic error may be unidentified prey. The smaller items are often most difficult to identify, and this means that much unidentifiable material is likely to be found when examining small species and younger stages of larger species. It follows that the mean prey size for small chaetognaths may be

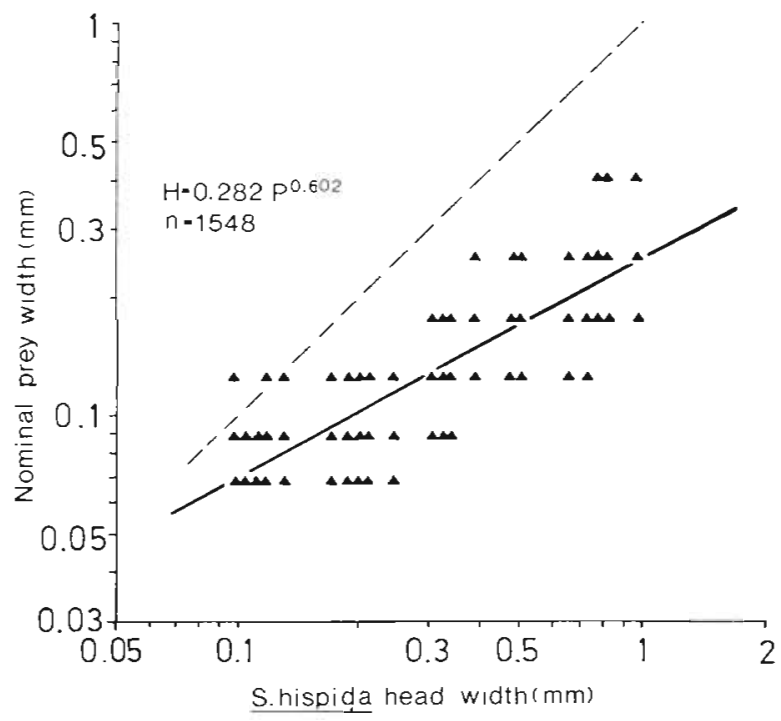

Fig. 7. Prey/predator size relation for Sagitta hispida. Weighted data reconstructed from Reeve and Walter (1972) 
overestimated, which results in an overestimate of the coefficient $a$ and/or an underestimate of the exponent b. Although $61 \%$ of the prey of Sagitta minima, the smallest Mediterranean species, were unidentifiable, they were relatively uniformly distributed over the age classes. Hence, while $b$ for this species may be reasonably well estimated, we should expect a very high a value (e.g. Table 6, Fig. 8). On the other hand, in $S$. friderici only $16 \%$ of the prey were unidentifiable, and most were in the smallest stage (35\% unidentified). These data, while giving a reasonable estimate of $a$, might be expected to yield an underestimate of $b$ (Table 6, Fig. 8). Together with the low significance found for this regression, the above consideration makes this low slope value highly suspect.

The large range of prey sizes which any given chaetognath can eat increases the prey size variance for any data set. This makes any determination of

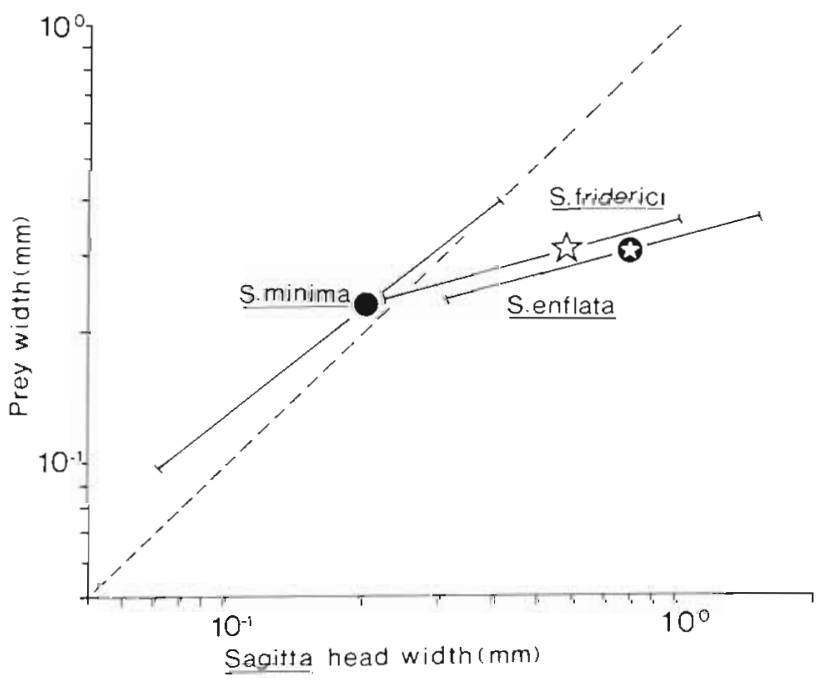

Fig. 8. Comparison of prey/predator size regressions for west Mediterranean species (Pearre, 1974, 1976). Bar length: chaetognath size range exponent uncertain unless a wide range of predator size classes are used. The technicians who pre-sorted the year-round Mediterranean collections ('Series B') appear to have overlooked small chaetognaths of all species. The limited size range of these collections is believed to be reponsible for the lack of significance of their regressions (Table 5). However, the observations appear to merge with those from 'Series A', which were not pre-sorted, and so the data sets for each species were combined (Figs 3, 4, 5).

Finally, the slope of the regression is affected by the natural availability of large prey. As discussed above, the smaller sizes of Sagitta elegans in the enclosed Bedford Basin have a prey/predator size relation very similar to that from open water. However, for the larger Sagitta in Bedford Basin there simply were not enough large copepods to continue optimal prey size selection. A prey size/predator size regression derived for one region cannot be indiscriminately used for other regions or seasons.

My data on prey of Sagitta enflata have a large amount of scatter (Fig. 5) and the regression derived from this has an unusually low slope (Table 6, Figs 5, 8). Feigenbaum (1979) found no relationship between sizes of $S$. enflata and their prey copepods in the Florida Current. Szyper (1976) examined a very dense population of small $(4-13 \mathrm{~mm}) \mathrm{S}$. enflata in Kaneohe Bay, Hawaii, and his data yield a significant relationship between prey and predator size (expressed as $\mathrm{N}$ or $\mathrm{P}$ content).

It seems likely that Feigenbaum's data are affected by lack of large prey, as he examined only large chaetognaths (11-25 mm) and Bsharah's (1957) data imply that the mean size of copepods in Feigenbaum's study area was less than the mean size found as prey. The low slope found for my Sagitta enflata data may also reflect lack of large prey, as the copepods in this area were mainly small species and $S$. enflata was the largest of the chaetognath species studied. Another

Table 6. Summary of prey size/predator size regressions for all Sagitta species reported as $H=a P^{b} ; H=$ prey body width; $P=$ chaetognath head width; $a, b=$ fitted constants

\begin{tabular}{|c|c|c|c|c|c|c|c|}
\hline \multirow[b]{2}{*}{ Species } & \multirow[b]{2}{*}{ No. prey } & \multirow[b]{2}{*}{ No. groups } & \multicolumn{4}{|c|}{ (Species ranked by decreasing 'b') } & \multirow[b]{2}{*}{ Source } \\
\hline & & & $a$ & $b$ & $r^{2}$ & $t$ & \\
\hline S. minima & 120 & 52 & 0.864 & 0.824 & 0.388 & $7.25^{\cdots}$ & This study \\
\hline S. elegans & 1276 & 20 & 0.622 & 0.766 & 0.358 & $11.35^{\cdots} \cdot$ & Rakusa-Suszczewski (1969) \\
\hline S. elegans (truncated) & 258 & 137 & 0.493 & 0.756 & 0.500 & $14.89 \cdots$ & This study \\
\hline S. hispida & 1548 & 21 & 0.282 & 0.602 & 0.766 & $20.66^{\cdots}$ & Reeve and Walter (1972) \\
\hline S. setosa & 124 & 12 & 0.482 & 0.577 & 0.366 & $4.85^{\cdots}$ & Rakusa-Suszczewski (1969) \\
\hline S. setosa & 366 & 10 & 0.388 & 0.520 & 0.289 & $6.47^{\cdots}$ & Mironov (1960) \\
\hline S. friderici & 157 & 53 & 0.362 & 0.283 & 0.044 & $2.57^{*}$ & This study \\
\hline S. enflata & 307 & 94 & 0.333 & 0.274 & 0.043 & $3.69 \cdots$ & This study \\
\hline \multicolumn{8}{|c|}{$=0.05>p>0.01 ; \cdots=p<0.001$} \\
\hline
\end{tabular}


factor which should contribute to a low slope estimate, however, is that $S$. enflata is a chaetognath with high water content and a low allometric exponent $\left[b_{p}=\right.$ 2.92 (Szyper, 1976), 3.15 (Feigenbaum, 1979) vs $b_{p}=$ 3.30 (Matthews and Hestad, 1977), 3.24 (Feigenbaum MS 1979) for $S$. elegans]. As shown above (Introduction), this should decrease the $b$ value of the prey width/predator mouth size relation even if $\beta$ (the prey weight/predator weight exponent) were constant. Comparing the regressions of the three Mediterranean species, however, (Fig. 8) it is tempting to speculate that $S$. minima, the smallest, was the best adapted to the food size spectrum. This may be reflected by the fact that it was by far the most abundant (Pearre, 1974).

The two regressions for prey size vs predator size in Sagitta setosa are interesting both for their obvious similarities and their differences. While neither data set shows much evidence of upper prey-size limitation, the sizes of both chaetognaths (Mironov, 1960; RakusaSuszczewski, 1969) and their prey (Petipa, 1957; Kanaeva, 1962; Studenikina and Cherapakhina, 1969, are smaller, as expected, in the warmer Black Sea. Thus the whole of Mironov's data set is shifted left and downward relative to that of Rakusa-Suszczewski (Fig. 9). However, the difference between the relationships for $S$. setosa and $S$. elegans for the same area (N. Atlantic) suggest real species characteristics.

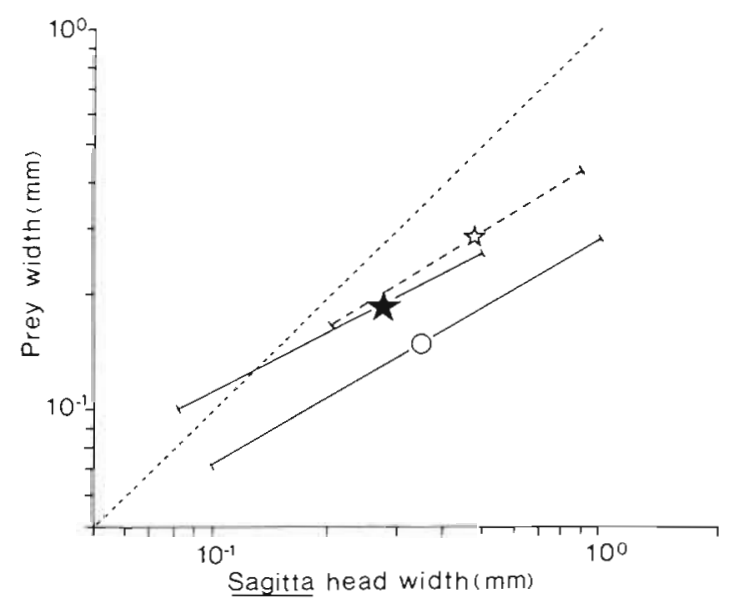

Fig. 9. Comparison of prey/predator size regressions for Sagitta setosa and S. hispida. Bar length: chaetognath size range. Open star: S. setosa from Rakusa-Suszczewski (1969); closed star: ditto from Mironov (1960); circle: S. hispida from Reeve and Walter (1972)

Reeve and Walter's (1972) experimental study of food size selection by Sagitta hispida may incorporate some biases due to restricted prey size distributions used to facilitate analysis. Nonetheless, the relationship fits the same model, with the exponent close to the mean for the various species, and very similar to those for the two regressions on S. setosa (Fig. 9). The position difference may be partially due to the underidentification of small prey in the field studies. Part of the difference, however, is probably due to the unusually large head size of $S$. hispida (Table 1) which has resulted in shifting its data set to the right relative to that of $S$. setosa of the same body size in this type of plot.

\section{CONCLUSIONS}

The power curve fit of mean prey size to predator size in chaetognaths, which was shown to be the theoretically expected relationship, appears to be justified in all cases. However, the specific coefficients and exponents found for any given species may vary between studies because of both experimental error (e.g. unidentified prey) and environmental factors (e.g. scarcity of large prey). Because of this, it is difficult to know if inherent differences in these relationships exist between species.

However, on the basis of the limited work which has been done on different species in the same areas, such species differences appear to be real. As major predators upon copepods, the size selection exercized by chaetognaths must have a considerable impact on the size structure of the whole plankton community.

Acknowledgements. I would like to thank G. C. H. Harding and S. R. Kerr for critical reviews of this manuscript. Partial funding for the work was supplied by a grant from the Chesapeake Bay Foundation.

\section{LITERATURE CITED}

Andréu, P. (1979). Quetognatos del Mediterráneo occidental en Octubre de 1972 (sic) Res. Exp. Cient. B/0 Cornide 8: $161-172$

Bsharah, L. (1957). Plankton of the Florida Current V. Environmental conditions, standing crop, seasonal and diurnal changes at a station forty miles east of Miami. Bull. mar. Sci. Gulf Caribb. 7: 201- 251

Dallot, S. (1978). Sur la présence du Chaetognate planctonique Sagitta setosa Müller 1847, dans les eaûx néritiques de Castellón. Investigación pesq. 42: 33-52

Feigenbaum, D. (1979). Daily ration and specific daily ration of the chaetognath Sagitta enflata. Mar. Biol. 54: 75-82

Feigenbaum, D. (MS 1979). Low temperature feeding by the chaetognath, Sagitta elegans, in Vinyard Sound, Massachusetts. Annu. Mtg. Am. Soc. Limnol. Oceanogr. Abstr. (unpubl.)

Kanaeva, I. P. (1962). The average weight of Copepoda of the central and northern Atlantic, Norwegian and Greenland seas (Russ.). Trudy V.N.I.R.O. 46: 253-266

Kerr, S. R. (1974). Theory of size distribution in ecological communities. J. Fish. Res. Bd Can. 31: 1859-1862

Kotori, M. (1976). The biology of Chaetognatha in the Bering 
Sea and the northern North Pacific ocean, with emphasis on Sagitta elegans. Mem. Fac. Fish. Hokkaido Univ. 23: 95-183

Lock, A. R. (1968). A laboratory and field study of the possible role of temperature in the vertical migrations of the copepod Pseudocalanus minutus (Krøyer). M.Sc. thesis, Dalhousie University, Canada

Mather, K. (1943). Statistical analysis in biology, Methuen, London

Matthews, J. B. L., Hestad, L. (1977). Ecological studies on the deep-water pelagic community of Korsfjorden, Western Norway. Length/weight relationships for some macroplanktonic organisms. Sarsia 63: 57-63

Mironov, G. N. (1960). Feeding of plankton predators. II. Feeding of Sagitta. (Russ.) Trudy Sevastopol biol. Sta. 13: $78-88$

Pearre, S., Jr. (1973). Vertical migration and feeding in Sagitta elegans Verrill. Ecology 54: 300-314

Pearre, S., Jr. (1974). Ecological studies of three westMediterranean chaetognaths. Investigación pesq. 38: 325-369

Pearre, S., Jr. (1976). A seasonal study of the diets of three sympatric chaetognaths. Investigación pesq. 40:1-16

Pearre, S., Jr. (1979). Problems of detection and interpretation of vertical migration. J. Plankton Res. 1: 29-44

Pearre, S., Jr. (1980). The copepod width/weight relation and its utility in food chain research (unpubl.)

Petipa, T. S. (1957). On the average weight of common forms of zooplankton in the Black Sea (Russ.). Trudy Sevastopol biol. Sta. 9: 39-57

Rakusa-Suszczewski, S. (1969). The food and feeding habits of chaetognaths in the seas around the British Isles. Pol. Arch. Hydrobiol. 13: 213-232

Reeve, M. R. (1970). The biology of chaetognaths. I. Quantitative aspects of growth and egg production in Sagitta hispida. In: Steele, J. H. (ed.) Marine foods chains, Oliver and Boyd, Edinburgh, pp. 168-189

Reeve, M. R., Walter, M. A. (1972). Conditions of culture, food-size selection, and the effects of temperature and salinity on growth rate and generation time in Sagitta hispida Conant. J. exp. mar. Biol. Ecol.9: 191-200

Ricker, W E. (1975). Computation and interpretation of biological statistics of fish populations. Bull. Fish. Res. Bd Can. 91: 1-382

Sheldon, R. W., Sutcliffe, W. H., Jr, Paranjape, M. A. (1977). Structure of pelagic fish chain and relationship between plankton and fish production. J. Fish. Res. Bd Can. 34: 2344-2353

Sokal, R. R., Rohlf, F. J. (1969). Biometry: the principles and practice of statistics in biological research, W. H. Freeman, San Francisco

Steele, J. H., Frost, B. W. (1977). The structure of plankton communities. Roy. Soc. London Philos. Trans. B: Biol. Sci. 280: 485-534

Studenikina, Ye. I., Cherepakhina, M. M. (1969). Average weight of the main forms of zooplankton in the Sea of Azov. Hydrobiol. J. 5: 74-76

Sullivan, B. K. (1980). In situ feeding behavior of Sagitta elegans and Eukrohnia hamata (Chaetognatha) in relation to the vertical distribution and abundance of prey at ocean station ' $\mathrm{P}$ '. Limnol. Oceanogr. 25: 317-326

Sverdrup, H. U., Johnson, M. W., Fleming, R. H. (1942). The oceans: their physics, chemistry, and general biology. Prentice-Hall, N. J.

Szyper, J. P. (1976). The role of Sagitta enflata in the southern Kaneohe Bay ecosystem. Ph. D. thesis, University of Hawaii, USA

Wemer, E. A. (1974). The fish size, prey size, handling time relation in several sunfishes and some implications. J. Fish. Res. Bd Can. 31: 1531-1536 